\title{
The Sertoli cell: Novel clinical potentiality
}

\author{
Paschalia K. Iliadou, Christos Tsametis, Athina Kaprara, \\ loannis Papadimas, Dimitrios G. Goulis
}

First Department of Obstetrics and Gynecology, Unit of Reproductive Endocrinology, Medical School, Aristotle University of Thessaloniki, Greece

\begin{abstract}
The Sertoli cell is important for endocrine and paracrine control of spermatogenesis. Functions attributed to Sertoli cells are: (1) supportive and trophic functions for the cells of the seminiferous epithelium, (2) transport of mature spermatids towards the lumen of seminiferous tubules, (3) secretion of androgen binding protein, (4) production of substances with endocrine or paracrine action for spermatogenesis control and (5) interaction with intertubular endocrine Leydig cells. Inhibin $B$ and anti-Müllerian hormone (AMH) are glycoproteins belonging to the transforming growth factor $\beta$ (TGF- $\beta$ ) superfamily; they are produced almost exclusively by the Sertoli cells and have been proposed as direct markers of their function and indirect markers of spermatogenesis. Serum inhibin B and AMH concentrations seem to constitute additional diagnostic parameters in male subfertility as they reflect Sertoli cell function. Stimulated concentrations of serum inhibin B and AMH do not add clinically relevant information in subfertile men compared to basal concentrations of these hormones. Serum inhibin $B$ and AMH concentrations correlate with testicular histology/cytology but are not superior to FSH as predictors of the presence of sperm in testicular sperm extraction (TESE)/fine needle aspiration (FNA) biopsy in men with azoospermia.
\end{abstract}

Key words: Anti-Müllerian hormone, Inhibin, Sertoli cell, Spermatogenesis, Testicular sperm extraction

\section{INTRODUCTION}

Approximately $10-20 \%$ of all couples experience subfertility problems, subfertility being defined as absence of conception after at least 12 months of

Address for correspondence:

Paschalia K. Iliadou, Unit of Reproductive Endocrinology, First Department of Obstetrics and Gynecology, Medical School, Aristotle University of Thessaloniki, Papageorgiou General Hospital, Ring Road, Nea Efkarpia, 56403 Thessaloniki, Greece, Tel.: +30 2310 693384, E-mail: paschaliailiadou@gmail.com Received: 28-10-2015, Accepted: 10-12-2015 unprotected intercourse. In $50 \%$ of these couples, a male factor can be identified. ${ }^{1,2}$ As disturbed spermatogenesis is the leading cause of male subfertility, assessment of the quality of spermatogenesis is the cornerstone in the evaluation and treatment of subfertile men. The Sertoli cell is the supporting cell of spermatogenesis and is important for its endocrine and paracrine control. ${ }^{3}$ The aims of this review are: (1) to present current knowledge concerning Sertoli cell structure and function, with emphasis on new markers of spermatogenesis, and (2) to apply this knowledge within the clinical setting. 


\section{SERTOLI CELL: STRUCTURE AND FUNCTION}

The parenchyma of the testes is divided by thin septula into conical lobules which consist of the seminiferous tubules and intertubular tissue. The seminiferous tubules are coiled loops whose two ends open into the spaces of the rete testis. The fluid secreted by the seminiferous tubules is collected in the rete testis and delivered to the ductal system of the epididymis. ${ }^{4}$ The seminiferous tubule consists of the germinal epithelium and the peritubular tissue (lamina propria). The germinal epithelium consists of cells that include different developmental stages of germ cells, namely spermatogonia, primary and secondary spermatocytes and spermatids. These are located within invaginations of Sertoli cells.

Originally described by Enrico Sertoli in 1865, the somatic Sertoli cell performs a crucial "nursing" function in connection with spermatogenesis. Functions attributed to Sertoli cells are: (1) supportive and trophic functions for the cells of the seminiferous epithelium, (2) transport of mature spermatids towards the lumen of seminiferous tubules, (3) secretion of androgen-binding protein (ABP), (4) production of substances with endocrine or paracrine action for spermatogenesis control and (5) interaction with intertubular endocrine Leydig cells. ${ }^{4}$

Sertoli cells are connected to each other by specialized zones of tight junctions of cellular membranes separating the germinal epithelium into a basal and an adluminal compartment. These tight junctions form the blood-testis barrier of the testis. During spermatogenesis, the germ cells pass this barrier entering the adluminal compartment where they find protection from diffusion of extraneous substances. ${ }^{4}$ Thus, the blood-testis barrier does not separate the blood from testicular tissue but rather constitutes a delicate boundary between diploid and haploid germ cells. A well-functioning Sertoli cell provides the developing germ cells with appropriate mitogens, differentiation factors and sources of energy as well as protecting them from harmful agents and from the host's own immune system. ${ }^{5}$ Sertoli cells produce: (1) transport proteins and enzymes, e.g. ABP, transferrin, ceruloplasmin, plasminogen activator (PA), (2) growth factors, e.g. transforming growth factors $\alpha$ and $\beta$ (TGF- $\alpha$, TGF- $\beta$ ), insulin-like growth factor
(IGF-1) and (3) hormones, such as inhibin B and anti-Müllerian hormone (AMH).

The first appearance of fetal Sertoli cells in the primitive gonad defines the initial stage in the development of the embryonic testis. These cells express the Sry gene, thereby determining the male sex of the gonad. As the exclusive source of AMH, Sertoli cells are also responsible for inhibiting the development of internal female genitalia. These cells together with another type of somatic testicular cell, the peritubular cell, are required for formation of the testis cords. The immature Sertoli cell differs extensively from the mature cell with respect to both morphology and biochemical activity. ${ }^{5}$ As puberty approaches, the Sertoli cells become elongated and tight junctions are established between them. They begin to produce seminiferous fluid, which results in the transformation of the testis cords into seminiferous tubules possessing a lumen. The differentiated mature Sertoli cell alters its pattern of protein expression, starting to produce, e.g. transferrin and the inflammatory cytokine interleukin-1 $\alpha$ (IL-1 $\alpha)$. Immature Sertoli cells divide constantly, but this proliferative activity declines as puberty progresses and after tight junctions have been formed Sertoli cells are considered to no longer exhibit proliferative capacity. ${ }^{5}$ Follicle Stimulating Hormone (FSH) is the major endocrine regulator of Sertoli cell function. The Sertoli cell is the only cell type in the testis that expresses receptors for this hormone which is necessary for adequate Sertoli cell proliferation. Spermatogenesis is dependent on the presence of an adequate intratesticular level of testosterone. Sertoli cells express the Androgen Receptor (AR), but germ cells do not, indicating that androgenic effects on the seminiferous epithelium are mediated via the Sertoli cell. AR is required for adequate functioning of the blood-testis barrier, as well as for meiosis and the post-meiotic development of germ cells, and its level of expression on Sertoli cells increases throughout the process of maturation. ${ }^{5}$

The intertubular space of the human testis contains the microvasculature, endocrine Leydig cells, nerve fibres and connective tissue cells. ${ }^{4}$ Leydig cells secrete hormones, mainly testosterone, into the vessels. The microvasculature of the intertubular space is divided into inter-Leydig cell capillaries of the arterial side, intramural capillaries in the peritubular wall of the 
seminiferous tubule and inter-Leydig cell capillaries of the venous side; ${ }^{4}$ thus, communication between Leydig and Sertoli cells exists establishing autocrine and/or paracrine regulation. ${ }^{4}$

\section{INHIBIN B AND AMH: STRUCTURE AND FUNCTION}

Inhibin B and AMH are glycoproteins belonging to the TGF- $\beta$ superfamily; they are produced almost exclusively by the Sertoli cells and have been proposed as direct markers of their function and indirect markers of spermatogenesis.

Inhibin is a glycoprotein hormone of gonadal origin which was first identified by its ability to negatively regulate FSH. Inhibin consists of two disulphide-linked subunits, a common $\alpha$ subunit and a $\beta$ subunit, the latter of which exists in two forms, $A$ and $B$ (designated $\beta A$ and $\beta B$, respectively) (Figure 1). Although many molecular forms are found in circulation, biological activity resides only in the dimeric forms, inhibin $\mathrm{A}$ $(\alpha-\beta A)$ and $B(\alpha-\beta B)$. Inhibin B is the major form produced in the human male, where inhibin $A$ is undetectable. ${ }^{6}$ The Sertoli cell is considered the predominant source of inhibin B. Sertoli cells produce and secrete inhibin $B$ into the circulation as a response to FSH stimulation. Serum inhibin B concentration
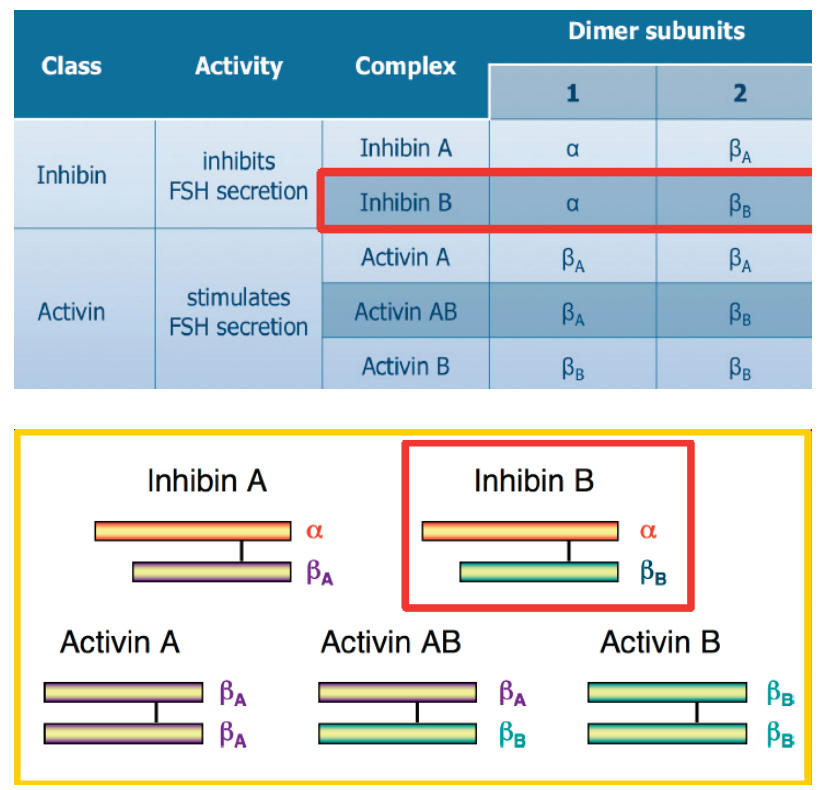

Figure 1. Inhibin family. is high during early postnatal life and then gradually declines to a still detectable plateau-level until the beginning of puberty when it again increases. ${ }^{5}$ During puberty, the regulatory mechanism of inhibin $\mathrm{B}$ secretion changes: instead of FSH, inhibin B is controlled by substances produced by the germ cells. Basal inhibin B increases under FSH stimulation in the first pubertal stages, when the last wave of Sertoli cell proliferation occurs, and a positive correlation between inhibin B and FSH is observed. ${ }^{7}$ At Tanner stages G3 and G4, however, FSH and inhibin B concentrations correlate negatively, suggesting that the negative feedback regulation loop is fully established at this stage of development. At puberty, when Sertoli cell proliferation ceases and spermatogenesis starts, the basal, adult inhibin B concentration is set and can be considered to be an index of Sertoli cell number and integrity. Once full spermatogenesis is ongoing, changes in inhibin B concentrations reflect mainly the status of germ cell proliferation and development and depend only secondarily on FSH. In adult life, inhibin B production is directly proportional to the "amount" of spermatogenesis, as shown by the direct correlation between serum inhibin B and sperm count. ${ }^{7}$

AMH was named for its effect of causing regression of the Müllerian ducts, the anlagen of the uterus, fallopian tubes and upper vagina. ${ }^{8} \mathrm{AMH}$ is a homodimeric disulfide-linked glycoprotein with a molecular weight of $140 \mathrm{kD}$. Sertoli cells produce high levels of AMH from the time of fetal testicular differentiation up to puberty, at which time AMH expression decreases. Three factors regulate AMH expression by Sertoli cells: testosterone, FSH and spermatocytes entering prophase of the first meiotic division. Testosterone is the most important; in its absence or in the event of androgen insensitivity due to mutation of the androgen receptor, serum AMH concentrations remain high and even increase at puberty. FSH has a stimulating effect upon $\mathrm{AMH}$ expression by Sertoli cells, which is visible only in the absence of androgens. Maturation of germ cells also has an effect upon the expression of AMH by Sertoli cells; Sertoli cells in tubules in which germ cells have initiated meiosis cease to produce AMH earlier than those in which neighboring germ cells are still immature. AMH is secreted bidirectionally by Sertoli cells: apically into the seminiferous tubules 
and basally toward the interstitium and the circulation. Serum concentrations of AMH are maintained at a high level until puberty, when they decrease dramatically, remaining very low during adulthood. ${ }^{9,10}$ After puberty, AMH is secreted preferentially by the apical pole of the Sertoli cell, resulting in higher concentrations of AMH in the seminal plasma than in serum. ${ }^{11}$ The higher concentrations of $\mathrm{AMH}$ in semen as compared to serum may reflect its role in spermatogenesis as well as sperm motility. Other actions of AMH in males include: (1) regulation of transabdominal testicular descent, (2) inhibition of aromatase action in Sertoli cells, (3) inhibition of differentiation of precursor forms to Leydig cells and (4) inhibition of steroidogenesis in Leydig cells.

\section{THE ROLE OF INHIBIN B AND AMH BASAL CONCENTRATIONS}

Serum inhibin B concentrations have been found to be significantly lower in men with testicular dysfunction compared with controls, as well as positively correlated with classical markers of spermatogenesis, such as sperm concentration, total sperm count and testicular volume. ${ }^{3,12-14}$ Serum AMH concentrations have been found to be significantly lower ${ }^{15,16}$ or equal ${ }^{17-19}$ in subfertile men compared with controls. Similarly, seminal AMH concentrations have been found to be significantly lower ${ }^{11,20-23}$ or equal ${ }^{15}$ in subfertile men compared with fertile controls. In order to further elucidate the role of inhibin B and AMH in male subfertility we designed a prospective control-matched study with the aim of determining serum inhibin $\mathrm{B}$ and $\mathrm{AMH}$ concentrations in men with different causes of subfertility. ${ }^{24}$ We prospectively studied 82 subfertile men and 31 controls. Based on the clinical, hormonal, sperm, imaging, testicular cytology and genetic results, an etiological classification of the 82 subfertile men was accomplished. We found that serum inhibin $\mathrm{B}$ and $\mathrm{AMH}$ concentrations were significantly lower in subfertile men compared to control men. Moreover, there were significant differences in inhibin B concentrations among the different groups of subfertile men, following a "progressive" pattern, with increasing concentrations as we moved from more severe (e.g. idiopathic non-obstructive azoospermia) to less severe testicular damage (e.g. varicocele). On the other hand, AMH concentrations were similar among men with different causes of subfertility, following an "all-or-nothing" pattern. This finding may suggest that $\mathrm{AMH}$ is more sensitive than inhibin B in that even a mild insult (e.g. varicocele) results in a drastic decrease in AMH production. In conclusion, serum inhibin B and AMH concentrations seem to constitute additional diagnostic parameters in subfertile men and may be especially useful in cases of equivocal increases in serum FSH concentrations as they denote the existence (AMH, inhibin B) and severity (inhibin B) of the damage of the seminiferous epithelium.

\section{THE ROLE OF INHIBIN B AND AMH STIMULATED CONCENTRATIONS}

Several studies that evaluated serum concentrations of inhibin B and AMH found wide overlaps between fertile and subfertile men. ${ }^{13,17,24-25}$ Very few studies have attempted to evaluate stimulated serum inhibin B concentrations after administration of FSH. ${ }^{26-29}$ We attempted to evaluate basal and stimulated serum inhibin $\mathrm{B}$ and $\mathrm{AMH}$ concentrations in men with non-obstructive azoospermia (NOA). ${ }^{30}$ Our initial hypothesis was that FSH administration would increase inhibin $\mathrm{B}$ and AMH concentrations in fertile controls but not in men with NOA; thus, the stimulated concentrations would prove to be better than basal concentrations in the discrimination between fertile controls and men with NOA. Thirty-seven men with NOA and 17 fertile controls were recruited and studied. All subfertile and control men underwent the Exogenous FSH SErtoli Reserve Test (EFSERT): estimation of serum inhibin $\mathrm{B}$ and $\mathrm{AMH}$ concentrations before, 24 and $48 \mathrm{~h}$ after administration of 300 international units (IU) of human recombinant FSH (hrFSH), intramuscularly. Basal inhibin B concentrations as well as inhibin B concentrations $24 \mathrm{~h}$ and $48 \mathrm{~h}$ after administration of $\mathrm{hrFSH}$ were lower in men with NOA as compared to controls. Similar differences at all time points were observed for serum AMH concentrations. However, in both NOA and control men, no change of serum inhibin B or AMH concentrations were recorded throughout the EFSERT. As demonstrated by this study ${ }^{30}$ as well as a review of literature, ${ }^{26-29}$ a bolus dose of up to $300 \mathrm{IU}$ of $\mathrm{hrFSH}$ is not sufficient to stimulate either inhibin B or AMH serum concentrations within the following $48 \mathrm{~h}$. As the stimulation 
of inhibin B by endogenous FSH is well established, it seems that much more prolonged administration (presumably multiple injections over a period of two to three weeks) is required in order to achieve a clinically meaningful inhibin B stimulation. Nevertheless, such an administration renders EFSERT an impractical diagnostic tool for the evaluation of men with NOA. The stimulatory effect of FSH on inhibin $\mathrm{B}$ and $\mathrm{AMH}$ could be attenuated, at least in the case of $\mathrm{AMH}$, by the normal testosterone concentrations in the group of men with NOA, as there is evidence that the suppressive effect of LH-driven testicular androgens outweighs the stimulatory effect of FSH on Sertoli cells. ${ }^{29}$ In conclusion, stimulated serum concentrations of inhibin B and AMH, as obtained by an EFSERT, do not contribute to the diagnostic evaluation of men with NOA as the same information can be acquired by the basal serum concentrations of these hormones. Therefore, given the present evidence, we cannot recommend the use of EFSERT in clinical practice.

\section{THE ROLE OF INHIBIN B AND AMH IN PREDICTION OF SPERM RETRIEVAL}

The introduction into clinical practice of assisted reproduction techniques such as intracytoplasmic sperm injection (ICSI) made fatherhood possible for men with NOA. The extraction of sperm from the testis through fine-needle aspiration (FNA) or open biopsy (testicular sperm extraction - TESE) can result in a favorable reproductive outcome. Nevertheless, all these procedures are invasive in nature with variable possibility of successful sperm extraction. As a consequence, a non-invasive test that could predict the presence of sperm in men with NOA would be of profound clinical importance. Until recently, FSH and testicular volume constituted the best options to make such a prediction. Therefore, we designed a cross-sectional study aiming to examine inhibin B and $\mathrm{AMH}$ as predictors of the recovery of sperm in testicular FNA performed in men with azoospermia and compare their predictive value with that of FSH and testicular volume. ${ }^{31}$ We prospectively recruited and studied 51 subfertile men with azoospermia. We found a significant correlation between inhibin $\mathrm{B}$ and cytological diagnosis, with inhibin B concentrations levels following a "progressive" pattern with declining concentrations as we moved from less severe (e.g. mild hypospermatogenesis) to more severe cytological diagnosis (e.g. Sertoli Cell-Only Syndrome). On the other hand, there was no significant correlation between cytological diagnosis and AMH (Figure 2). Receiver operating characteristic (ROC) curves were constructed using testicular FNA as the reference method (presence or absence of sperm). The Area Under Curve (AUC) was 0.610 for inhibin B, 0.565 for $\mathrm{AMH}, 0.714$ for $\mathrm{FSH}$ and 0.693 for testicular volume. In pairwise comparison of ROC curves, there was no statistically significant difference among AUCs. Therefore, none of the four parameters was superior to the others. No significantly better sperm retrieval predictions were obtained with combination of the study variables (Figure 3 ). In conclusion, this study ${ }^{31}$ did not provide evidence that serum inhibin $\mathrm{B}$ and $\mathrm{AMH}$ concentrations are superior to FSH or testicular volume as predictors of the presence of sperm in testicular FNA in men with azoospermia.

A series of studies that attempted to estimate the predictive value of serum or seminal inhibin $B$ or $\mathrm{AMH}$ as non-invasive markers of persistent spermatogenesis in men with NOA have reported contradictory results. Therefore, we attempted to estimate this predictive value through a systematic review of diagnostic accuracy studies published in the literature and a meta-analysis of the best evidence available. ${ }^{32}$ Studies which provided data on the accuracy of serum or seminal AMH and/or serum or seminal inhibin B (index tests) for the prediction of the presence of spermatozoa in sperm retrieval techniques in men with azoospermia were considered potentially eligible. Studies were included in the meta-analysis only if TESE (reference standard) was performed in men with NOA. After combining data regarding men with NOA from nine studies (a total of 726 men), serum inhibin B demonstrated a sensitivity of 0.65 (95\% confidence interval [CI] 0.56-0.74) and a specificity of 0.83 (CI $0.64-0.93$ ) for the prediction of the presence of spermatozoa in TESE (Figure 4). A summary of the ROC (sROC) curve, along with a 95\% confidence contour, is presented in Figure 5 . The sROC-AUC was calculated at 0.73 (CI: 0.69-0.77). No clear conclusions can be deduced for seminal inhibin B and serum/seminal AMH due to the small number of relative studies. Although limited, current 
(a)

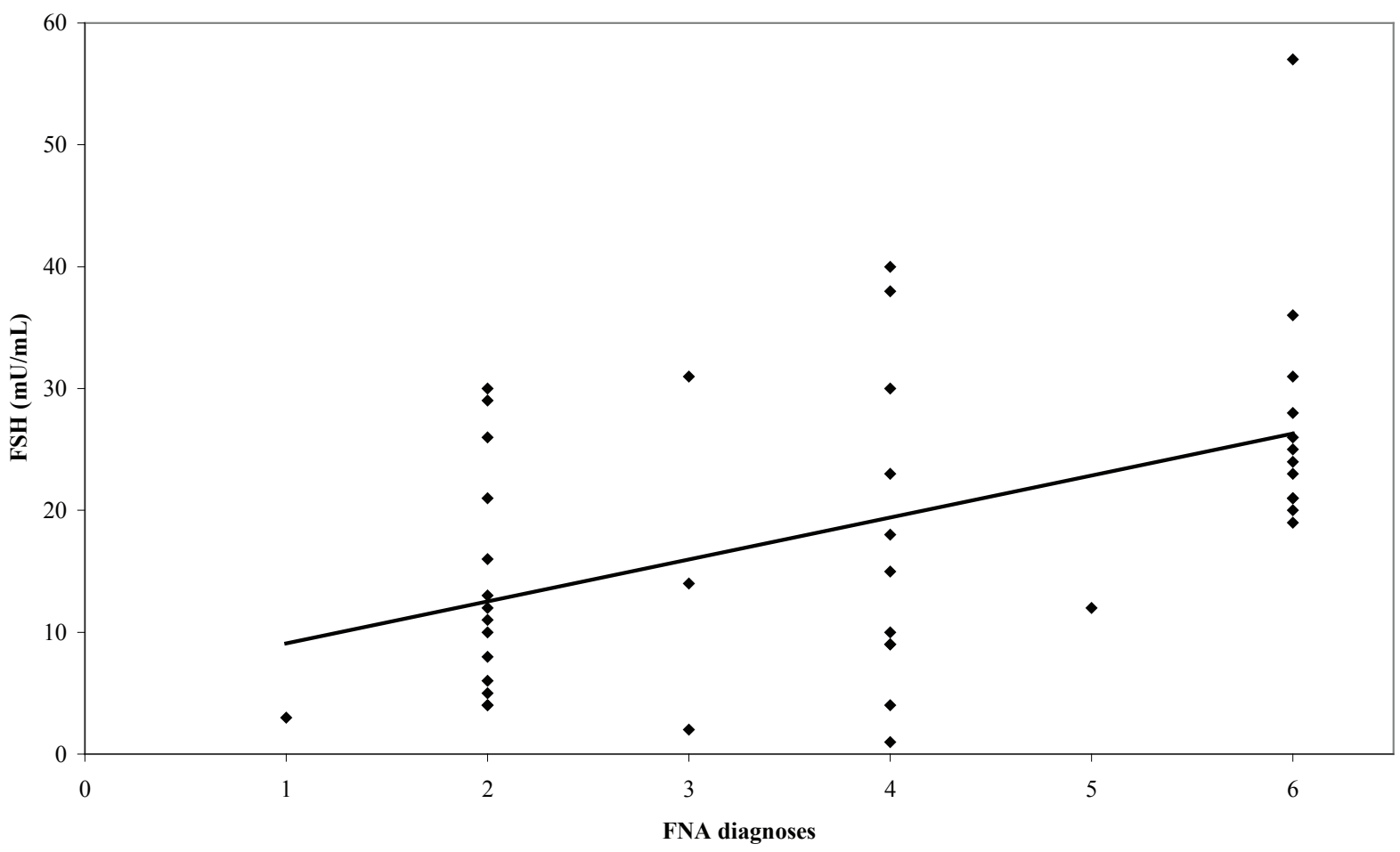

(b)

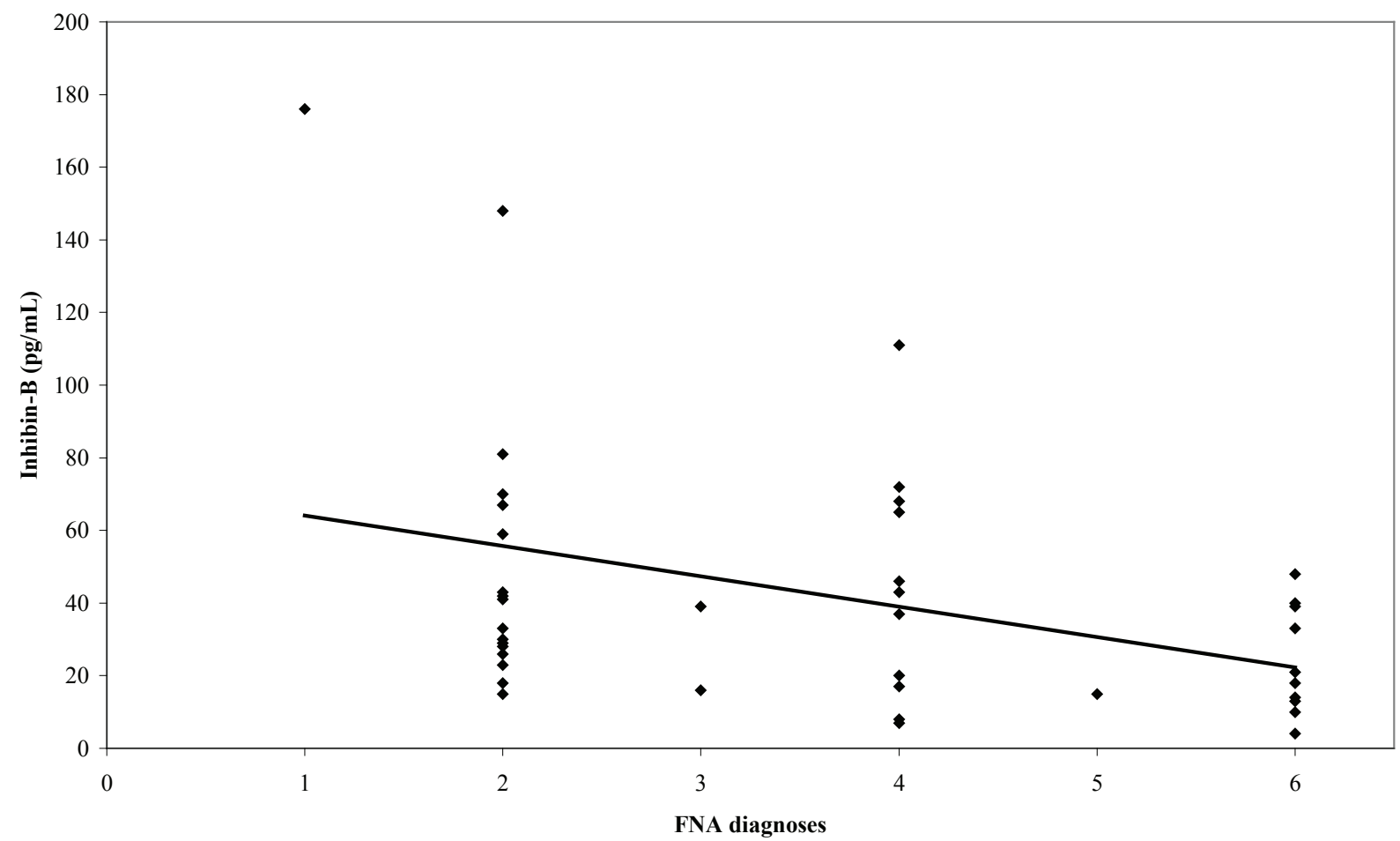

Figure 2. Scatter diagram and regression line of (a) FSH, (b) inhibin-B, (c) AMH concentrations and (d) volume of the larger testis versus FNA diagnoses (1: normal spermatogenesis, 2: hypospermatogenesis, 3: spermatogenesis arrest, incomplete, 4: spermatogenesis arrest, complete, 5: SCOS, incomplete, 6: SCOS, complete). ${ }^{31}$ 
(c)

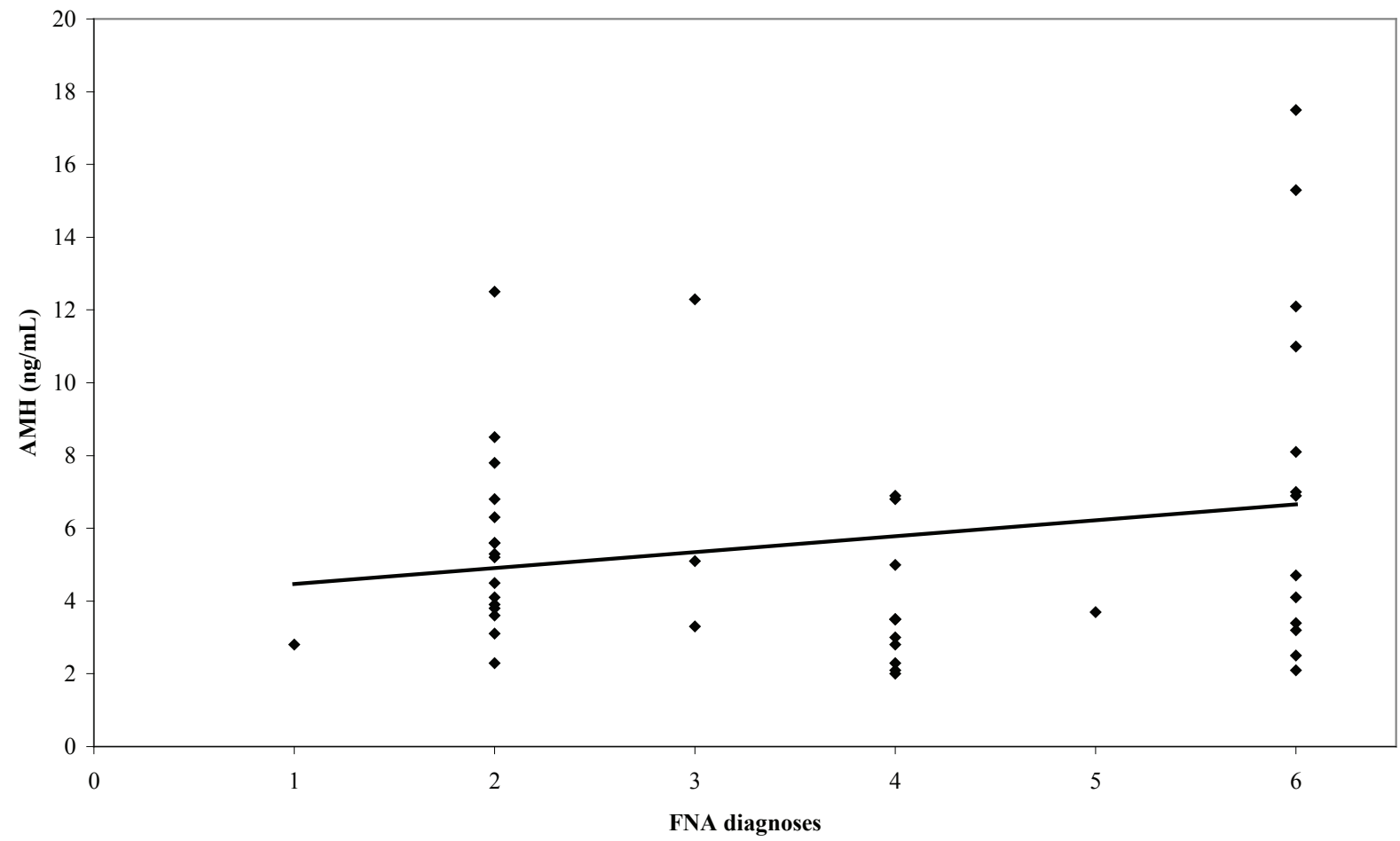

(d)

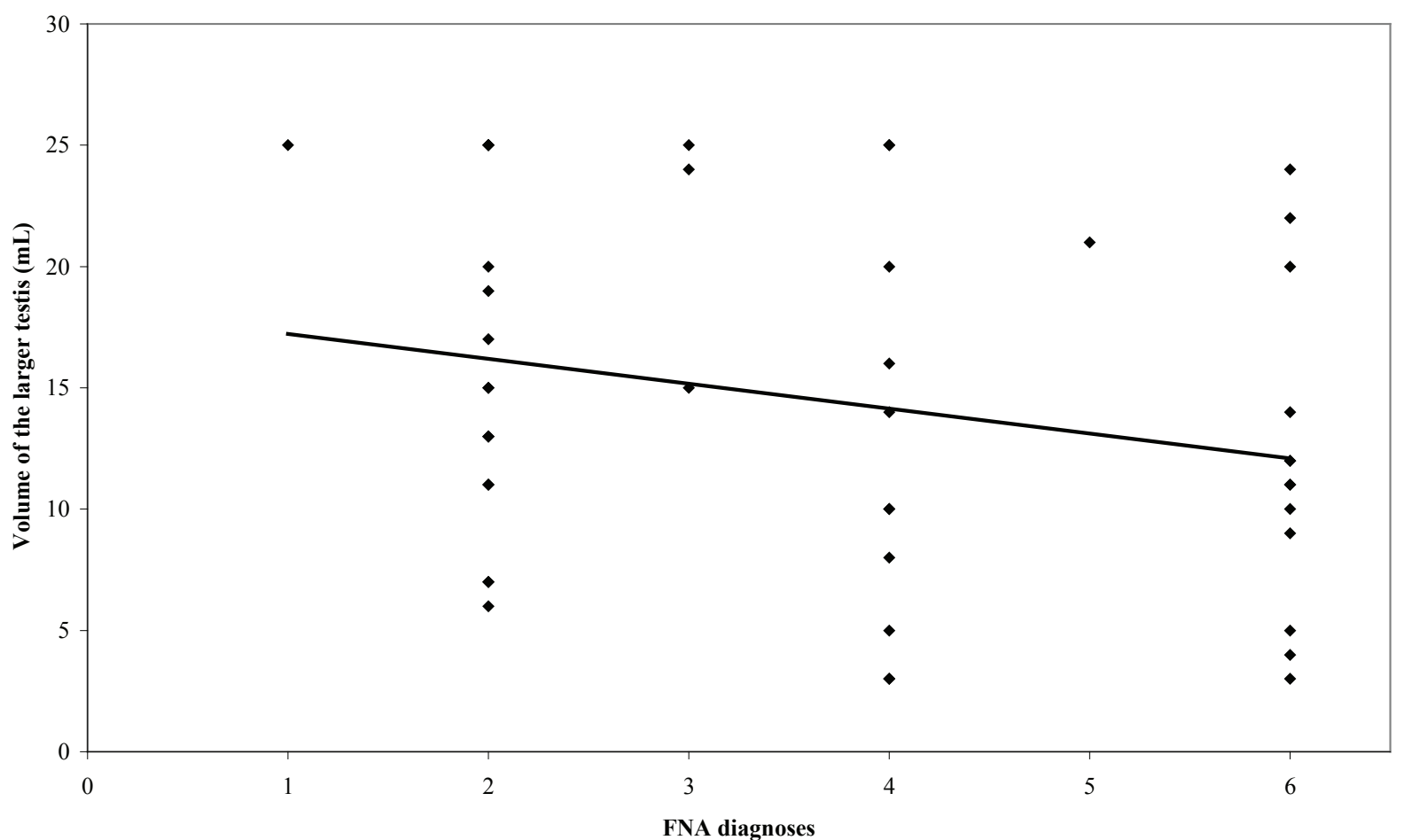

Figure 2. Scatter diagram and regression line of (a) FSH, (b) inhibin-B, (c) AMH concentrations and (d) volume of the larger testis versus FNA diagnoses (1: normal spermatogenesis, 2: hypospermatogenesis, 3: spermatogenesis arrest, incomplete, 4: spermatogenesis arrest, complete, 5: SCOS, incomplete, 6: SCOS, complete). ${ }^{31}$ 
(a)

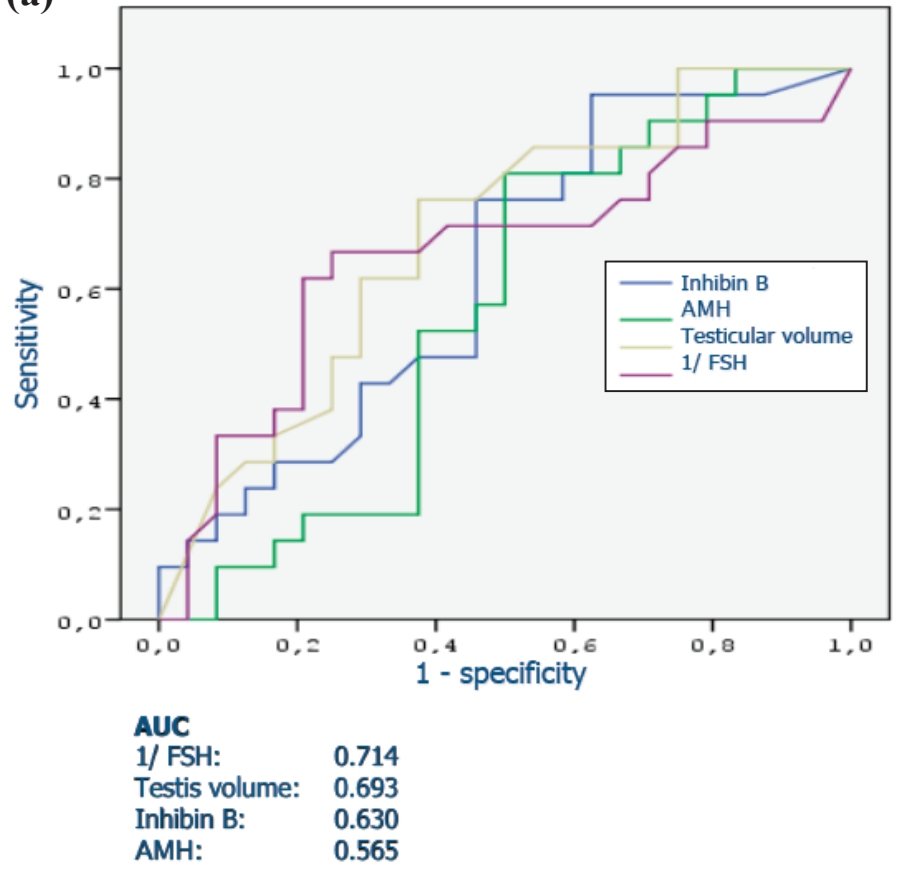

(b)

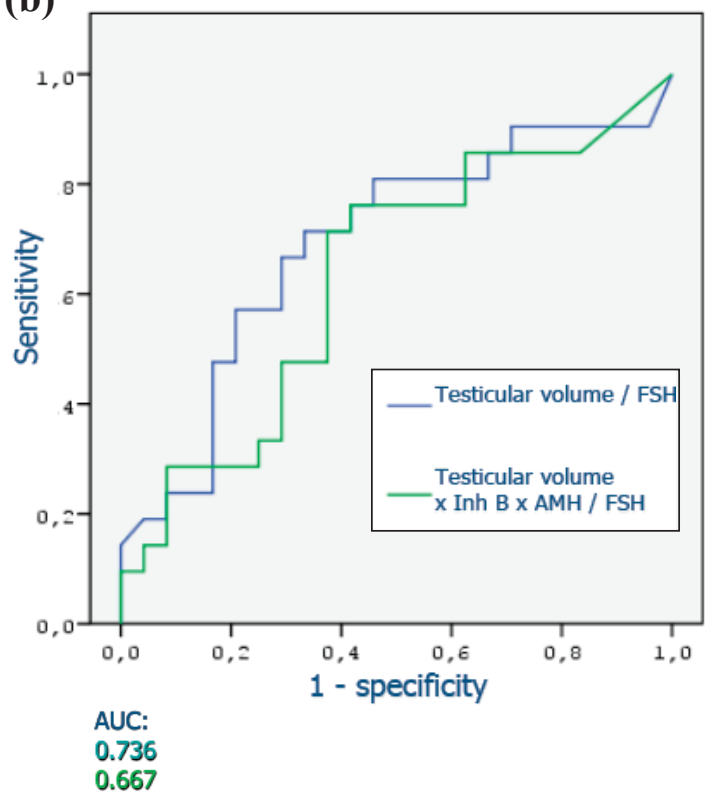

Figure 3. Receiver operating characteristic (ROC) curves of (a) FSH, testicular volume, inhibin B, AMH and (b) combinations of parameters, for sperm retrieval in testicular FNA.

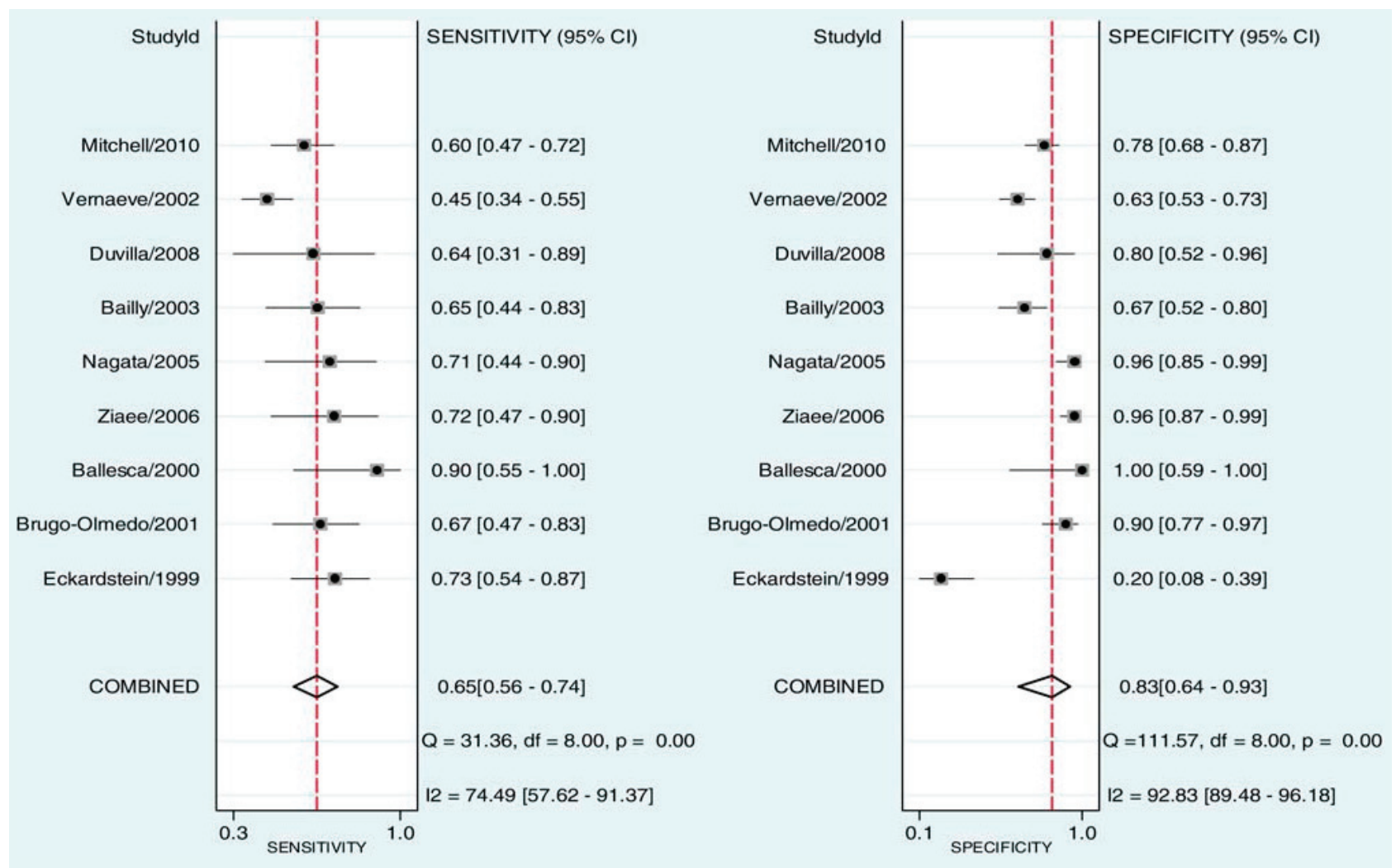

Figure 4. Sensitivity and specificity of serum inhibin B for the prediction of the presence of spermatozoa in patients with non-obstuctive azoospermia. ${ }^{32}$ StudyId refers to each study's first author and year of publication. 


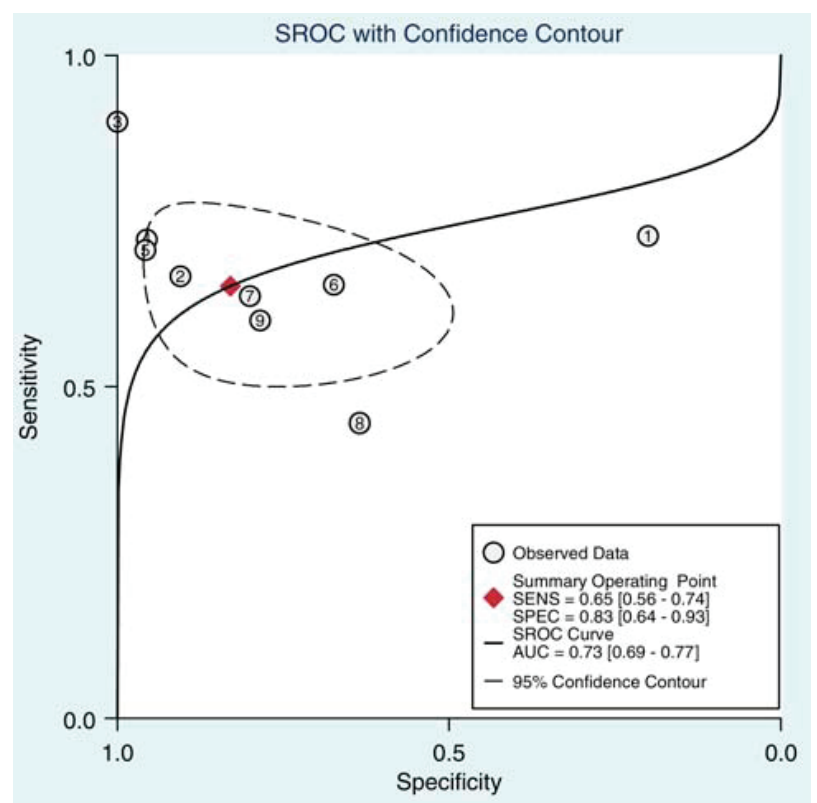

Figure 5. Summary of ROC (SROC) curve with 95\% confidence contour of serum inhibin $\mathrm{B}$ for the prediction of the presence of spermatozoa in patients with non-obstructive azoospermia. Numbers 1 to 8 correspond to individual studies. SENS: sensitivity, SPEC: specificity, AUC: area under curve. ${ }^{32}$

evidence does not support the diagnostic value of either seminal inhibin B or serum/seminal AMH. In an attempt to investigate whether inhibin B is superior to FSH as a predictor of sperm retrieval, we performed a comparative analysis of the two hormones, in eight studies, where data were available. FSH demonstrated a sensitivity of 0.71 and a specificity of 0.62 as compared with 0.65 and 0.85 , respectively for inhibin B. Thus, despite the similar overall diagnostic performance of the two hormones (sROC-AUC 0.70 versus 0.74 for both of them), inhibin B might be better in correct identification of men with NOA and no spermatogenesis (higher specificity), whereas FSH is better in correct identification of men with NOA and foci of spermatogenesis (higher sensitivity). Even in the case that all available parameters (testicular size, FSH, inhibin B) suggest low probability of successful sperm retrieval, the majority of men, at least in our practice, will decide to undergo a TESE procedure in an attempt to perform ICSI using their own genetic material. For this reason, we have applied a Fagan nomogram in order to counsel these men according to the principles of evidence based medicine (Figure 6). In the studies included in the present meta-analysis

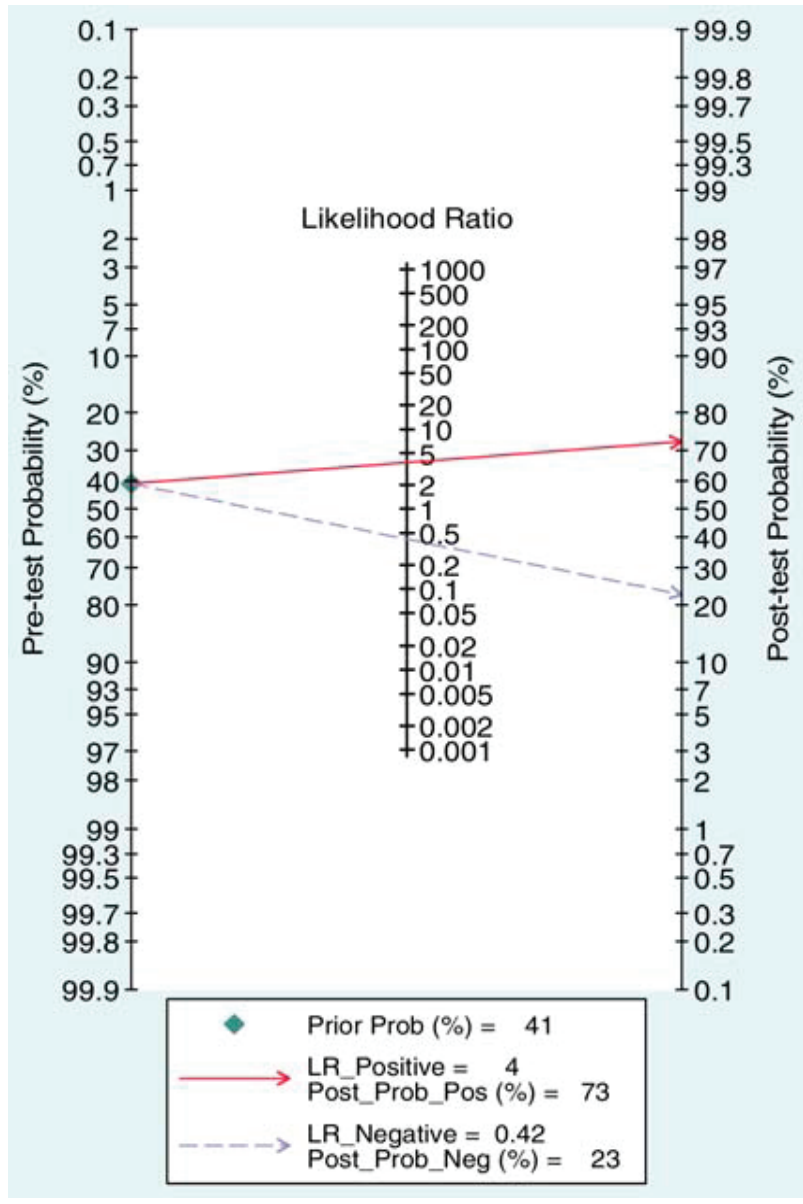

Figure 6. Fagan's (Bayesian) nomogram of serum inhibin B for the prediction of the presence of spermatozoa in patients with non-obstructive azoospermia. ${ }^{32}$

the pre-test probability of successful sperm retrieval was $41 \%$. In the event of favorable (i.e. high) serum inhibin B concentrations, this probability increases to $73 \%$ (Figure 6, solid line), whereas in the opposite case, it decreases to $23 \%$ (Figure 6, dotted line). In the case of the later, an alternative option, such as donor sperm, could be available.

\section{CONCLUSIONS}

Serum inhibin B and AMH concentrations seem to constitute additional diagnostic parameters in male subfertility as they reflect Sertoli cell function. Stimulated concentrations of serum inhibin B and AMH do not add clinically relevant information regarding subfertile men compared to basal concentrations of these hormones. Serum inhibin B and AMH concentra- 
tions correlate with testicular histology/cytology but are not superior to FSH as predictors of the presence of sperm in TESE/FNA in men with azoospermia.

\section{CONFLICT OF INTEREST}

None.

\section{REFERENCES}

1. World Health Organisation 2000 WHO manual for the standardized investigation, diagnosis and management of the infertile male. Cambridge University Press, Cambridge.

2. Bhasin S, 2007 Approach to the infertile man. J Clin Endocrinol Metab 92: 1995-2004.

3. Pierik FH, Burdorf A, de Jong FH, Weber RF, 2003 Inhibin B: a novel marker of spermatogenesis. Ann Med 35: 12-20.

4. Holstein AF, Schulze W, Davidoff M, 2003 Understanding spermatogenesis is a prerequisite for treatment. Reprod Biol Endocrinol 1: 107.

5. Petersen C, Soder O, 2006 The Sertoli cell--a hormonal target and 'super' nurse for germ cells that determines testicular size. Horm Res 66: 153-161.

6. Illingworth PJ, Groome NP, Byrd W, et al, 1996 InhibinB: a likely candidate for the physiologically important form of inhibin in men. J Clin Endocrinol Metab 81: 1321-1325.

7. Meachem SJ, Nieschlag E, Simoni M, 2001 Inhibin $\mathrm{B}$ in male reproduction: pathophysiology and clinical relevance. Eur J Endocrinol 145: 561-571.

8. Lee MM, Donahoe PK, 1993 Mullerian inhibiting substance: a gonadal hormone with multiple functions. Endocr Rev 14: 152-164.

9. Teixeira J, Maheswaran S, Donahoe PK, 2001 Müllerian inhibiting substance: an instructive developmental hormone with diagnostic and possible therapeutic applications. Endocr Rev 22: 657-674.

10. Lee MM, Donahoe PK, Hasegawa T, et al, 1996 Mullerian inhibiting substance in humans: normal levels from infancy to adulthood. J Clin Endocrinol Metab 81: 571-576.

11. Fenichel P, Rey R, Poggioli S, Donzeau M, Chevallier D, Pointis G, 1999 Anti-Mullerian hormone as a seminal marker for spermatogenesis in non-obstructive azoospermia. Hum Reprod 14: 2020-2024.

12. Anawalt BD, Bebb RA, Matsumoto AM, et al, 1996 Serum inhibin B levels reflect Sertoli cell function in normal men and men with testicular dysfunction. J Clin Endocrinol Metab 81: 3341-3345.

13. Jensen TK, Andersson AM, Hjollund NH, et al, 1997 Inhibin $\mathrm{B}$ as a serum marker of spermatogenesis: correlation to differences in sperm concentration and follicle-stimulating hormone levels. A study of 349 Danish men. J Clin Endocrinol Metab 82: 4059-4063.

14. Pierik FH, Vreeburg JT, Stijnen T, De Jong FH, Weber RF, 1998 Serum inhibin B as a marker of spermatogenesis. J Clin Endocrinol Metab 83: 3110-3114.

15. Al-Qahtani A, Muttukrishna S, Appasamy M, et al, 2005 Development of a sensitive enzyme immunoassay for anti-Mullerian hormone and the evaluation of potential clinical applications in males and females. Clin Endocrinol (Oxf) 63: 267-273.

16. Muttukrishna S, Yussoff H, Naidu M, et al, 2007 Serum anti-Mullerian hormone and inhibin B in disorders of spermatogenesis. Fertil Steril 88: 516-518.

17. Isikoglu M, Ozgur K, Oehninger S, Ozdem S, Seleker M, 2006 Serum anti-Mullerian hormone levels do not predict the efficiency of testicular sperm retrieval in men with non-obstructive azoospermia. Gynecol Endocrinol 22: 256-260.

18. Appasamy M, Muttukrishna S, Pizzey AR, et al, 2007 Relationship between male reproductive hormones, sperm DNA damage and markers of oxidative stress in infertility. Reprod Biomed Online 14: 159-165.

19. Tuttelmann F, Dykstra N, Themmen AP, Visser JA, Nieschlag E, Simoni M, 2009 Anti-Mullerian hormone in men with normal and reduced sperm concentration and men with maldescended testes. Fertil Steril 91: 1812-1819.

20. Fallat ME, Siow Y, Belker AM, Boyd JK, Yoffe S, MacLaughlin DT, 1996 The presence of mullerian inhibiting substance in human seminal plasma. Hum Reprod 11: 2165-2169.

21. Fujisawa M, Yamasaki T, Okada H, Kamidono S, 2002 The significance of anti-Mullerian hormone concentration in seminal plasma for spermatogenesis. Hum Reprod 17: 968-970.

22. Mostafa T, Amer MK, Abdel-Malak G, et al, 2007 Seminal plasma anti-Mullerian hormone level correlates with semen parameters but does not predict success of testicular sperm extraction (TESE). Asian J Androl 9: 265-270.

23. Duvilla E, Lejeune H, Trombert-Paviot B, Gentil-Perret A, Tostain J, Levy R, 2008 Significance of inhibin $\mathrm{B}$ and anti-Mullerian hormone in seminal plasma: a preliminary study. Fertil Steril 89: 444-448.

24. Goulis DG, Iliadou PK, Tsametis C, et al, 2008 Serum anti-Müllerian hormone levels differentiate control from subfertile men but not men with different causes of subfertility. Gynecol Endocrinol 24: 158-160.

25. Andersson AM, Petersen JH, Jorgensen N, Jensen TK, Skakkebaek NE, 2004 Serum inhibin B and folliclestimulating hormone levels as tools in the evaluation of infertile men: significance of adequate reference values from proven fertile men. J Clin Endocrinol Metab 89: 2873-2879.

26. Adamopoulos D, Kapolla N, Nicopoulou S, Pappa A, Koukkou E, Gregoriou A, 2003 Assessment of Sertoli 
cell functional reserve and its relationship to sperm parameters. Int J Androl 26: 215-225.

27. Foresta C, Bettella A, Merico M, Garolla A, Ferlin A, Rossato M, 2002 Use of recombinant human folliclestimulating hormone in the treatment of male factor infertility. Fertil Steril 77: 238-244.

28. Kinniburgh D, Anderson RA, 2001 Differential patterns of inhibin secretion in response to gonadotrophin stimulation in normal men. Int J Androl 24: 95-101.

29. Young J, Chanson P, Salenave S, et al, 2005 Testicular anti-Mullerian hormone secretion is stimulated by recombinant human FSH in patients with congenital hypogonadotropic hypogonadism. J Clin Endocrinol Metab 90: 724-728.

30. Tsametis C, Mintziori G, Iliadou PK, Tarlatzis BC,
Papadimas I, Goulis DG, 2011 Dynamic endocrine test of inhibin B and anti-Müllerian hormone in men with non-obstructive azoospermia. Gynecol Endocrinol 27: 661-665.

31. Goulis DG, Tsametis C, Iliadou PK, et al, 2009 Serum inhibin $\mathrm{B}$ and anti-Müllerian hormone are not superior to follicle-stimulating hormone as predictors of the presence of sperm in testicular fine-needle aspiration in men with azoospermia. Fertil Steril 91: 1279-1284.

32. Toulis KA, Iliadou PK, Venetis CA, et al, 2010 Inhibin $\mathrm{B}$ and anti-Mullerian hormone as markers of persistent spermatogenesis in men with non-obstructive azoospermia: a meta-analysis of diagnostic accuracy studies. Hum Reprod Update 16: 713-724. 